\title{
Familial palindromic rheumatism: a possible association with HLA
}

\author{
A. PINES, N. KAPLINSKY, S. ORGAD, E. GAZIT, AND O. FRANKL \\ From the Chaim Sheba Medical Center, Tel-Hashomer, Israel
}

SUMmaRY Palindromic rheumatism is very rare in children. The familial occurrence of the disease has been only briefly reported previously. A family is described here in which the mother and her 3 children suffered from typical palindromic rheumatism, which ran a benign course. All 4 members were seronegative and the HLA types of the children were identical. The HLA genotype of the mother was HLA A2, Cw4, Bw41, Bw6, DR5, MT2/Aw32, CX, Bw44, Bw4, DR1, MT1. HLA DR5 has previously been found to be associated with juvenile rheumatoid arthritis, while DR1 in Jews is significantly associated with adult-onset rheumatoid arthritis. DR5 was shared by the mother and her 3 children. The presence of the antigen DR5 in this sibship suggests that palindromic rheumatism may be a variant of juvenile rheumatoid arthritis with a relatively late onset and a more benign course. Tissue typing of patients with palindromic rheumatism may give a clue to prognosis. The patients' youth and the familial involvement, with identical HLA characteristics, are the outstanding features of this family.

Palindromic rheumatism (PR) is characterised by repeated attacks of inflammation in and near a joint, lasting from hours to days and subsiding completely without residual disabilities. ${ }^{1} \mathrm{~A}$ family incidence has been mentioned only twice previously. ${ }^{2}{ }^{3}$ We present a mother and her 3 children who suffered from PR, which ran a benign course. The children were of identical HLA types.

\section{Materials and methods}

HLA ABC typing was performed by the standard National Institutes of Health (NIH) 2-stage microlymphocytotoxicity technique. ${ }^{4}$ DR typing was performed on nylon-wool separated B lymphocytes by the extended incubation technique. ${ }^{5}$ Local, NIH, and 8th International Histocompatibility Workshop alloantisera were used for HLA ABC and DR antigen typing.

\section{Case reports}

CASE 1

A 43-year-old mother of 3 children visited the rheumatological clinic to accompany her son (case 2) for a check-up. When inquiring into family history of

Accepted for publication 25 November 1982.

Correspondence to Dr A. Pines, Internal Medicine F, Chaim Sheba Medical Center, Tel-Hashomer 52621, Israel. her son we found that since the age of 20 his mother had suffered from frequent attacks of monoarthritis. The attacks were characterised by pain, swelling, and redness lasting 2 to 4 days and appearing in and around one joint at a time. The affected joints were mainly the wrists and the knees. She had been admitted to hospital twice for evaluation of the arthritis. The only physical findings were transient swelling, tenderness, and redness of the affected joints. The complete blood count, differential count, serum uric acid, calcium, phosphorus, albumin, and globulin were all within the normal limits. The latex fixation test was negative, and LE cells were not found. Her family history and past history were not significant.

The patient was diagnosed as having palindromic rheumatism and was advised to take aspirin during attacks. She had been suffering from arthritis for nearly 10 years, and then a gradual decrease in the frequency and the severity of the attacks was noted until they subsided completely. There had been no recurrence for 13 years up to the time she came to us accompanying her son.

Her HLA phenotype was A2, Aw32, Cw4, Bw44, Bw4, Bw6, DR1, DR5, MT1, MT2 (Fig. 1).

\section{CASE 2}

A 15 -year-old boy, son of case 1 , was suffering from recurrent attacks of acute arthritis which started at the age of 12 . His past history was noncontributory. 


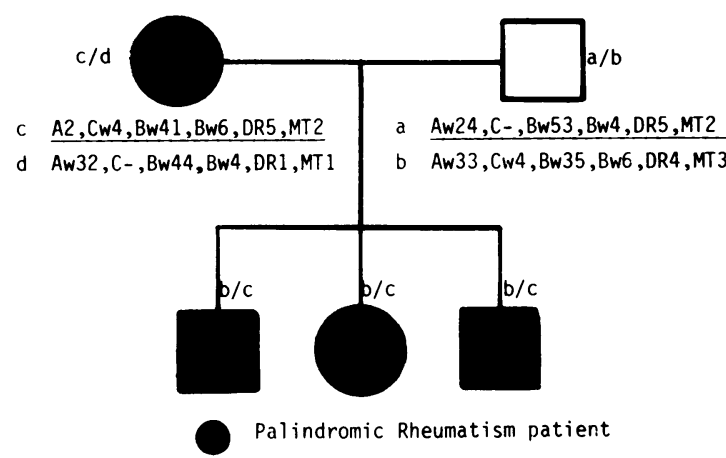

Fig. 1 HLA typing of family.

At first only the right knee was affected, but later the left knee, wrists, and elbows were affected also. The attacks appeared every 2 to 3 months and consisted of swelling, redness, and limited movement at the inflamed joint; they lasted 4 to 5 days, leaving no residual damage. During attacks laboratory tests showed that the erythrocyte sedimentation rate (ESR), blood count, serum uric acid, calcium, phosphorus, albumin, and globulin were all within normal limits. Tests for antinuclear factor (ANF) and rheumatoid factor (RF) were negative. Tissue typing showed that he was carrying the haplotypes b/c (Fig. 1).

Ibuprofen $400 \mathrm{mg} 3$ times daily was recommended during attacks. Now, over 3 years after the first attack, it seems that they have become shorter, milder, and less frequent.

\section{ASE 3}

a 13-year-old girl, sister of case 2, suffered from mild attacks of monoarthritis which started at the age of 8 . The attacks involved the hip joints, knees, elbows, wrists, and metacarpophalangeal joints and lasted one to 3 days; they were characterised by redness, swelling, and limitation of movement at the affected joints. She was completely well between the attacks, and physical examination showed no abnormalities. Laboratory tests during attacks showed that the ESR, blood count, serum uric acid, calcium, phosphorus, albumin, globulin, and urine analysis were within normal limits. Latex fixation and antinuclear factor (ANF) were negative. HLA typing showed the haplotypes b/c (Fig. 1).

Although she had recently noted a decrease in the frequency and the severity of the attacks, she was still taking indomethacin $25 \mathrm{mg} 3$ times daily during the attacks.

CASE 4

A 10 -year-old boy, the youngest child of case 1, was suffering from recurrent episodes of monoarthritis which started at the age of 8 . His past history was insignificant except for herpetic keratitis 3 years previously. The symptoms during the arthritic attacks were a raised systemic temperature and redness and swelling in and near the affected joints, usually the knee or the elbow. During attacks a transient increase in ESR had been noted, but the blood count, serum uric acid, calcium, phosphorus, albumin, globulin, and urine analysis were all within normal limits. The ANF and latex fixation tests were negative. HLA typing showed that he was also carrying the haplotypes b/c (Fig. 1).

The patient was treated with ibuprofen $200 \mathrm{mg} 3$ times daily. Although the interval between attacks was not uniform, it was continually becoming longer.

CASE 5

The father of the above children never had any arthritic complaints. His HLA antigens were (Fig. 1): Aw24, Aw33, Cw4, Bw53, Bw35, Bw4, Bw6, DR5, DR4, MT2, MT3.

\section{Discussion}

Palindromic rheumatism (PR), first described by Hench and Rosenberg, ${ }^{6}$ is diagnosed in $1 \%$ of patients with inflammatory joint complaints. ${ }^{1}$ It is characterised by recurrent afebrile attacks, with pain, swelling, redness, and disability, usually in or near one joint, large or small. It generally affects adults of either sex, causes little or no constitutional reactions, and is not associated with radiological or laboratory abnormalities. ${ }^{1}$ Follow-up studies show that half of the patients become seropositive within 10 years of the first attack, ${ }^{7}$ and more than a third evolve into classical rheumatoid arthritis (RA). ${ }^{23}$ Complete recovery can occur despite positive serology. ${ }^{8}$ Serum complement levels are usually normal and immune complexes are not found, ${ }^{9}$ but when these tests do give abnormal results the likelihood of the future development of RA is significantly raised. ${ }^{9}$ Other symptoms and signs of a possible transformation into RA are residual clinical and radiological joint abnormalities and raised ESR.

Treatment with anti-inflammatory drugs is usually sufficient, but on rare occasions chloroquine, ${ }^{10}$ gold, ${ }^{2}$ and penicillamine ${ }^{1112}$ have been successful.

The aetiology of PR is still obscure. Since joint disease may sometimes follow infection, serum antibody levels against the common viruses have been examined but found to be normal. ${ }^{1}$ However, the infectious theory is not disproved, and there may be allergic reactions yet to be discovered. ${ }^{13}$

A family history of joint disease in patients with $P R$ has previously been reported only twice but was not deeply investigated..$^{2}$ The family described here had some notable clinical features: all 4 affected members had typical attacks of PR, and, as expected in 
seronegative patients, the course of their disease was benign, and they responded well to antiinflammatory drugs.

The mother has had a complete remission for 13 years and her children's attacks were ameliorating with time. The first arthritic episode in each of the children occurred at an earlier age than would be expected from previous reports. ${ }^{1-3}$

This study, the first to display the HLA antigens of an entire family that suffered from benign PR, shows clearly that all the affected children had identical HLA types, carrying the haplotypes b/c (Fig. 1).

The maternal HLA genotype included both DR1 and DR5. DR1, which has been found in Jews to be associated with adult onset rheumatoid arthritis, ${ }^{14}$ was not present in the chromosome that was inherited by the children. DR5, which was previously shown to be associated with juvenile rheumatoid arthritis, ${ }^{15}{ }^{16}$ was shared by the mother and her 3 affected children. The presence of DR5 may suggest that palindromic rheumatism is a previously unrecognised variant of juvenile rheumatoid arthritis, having a late onset and a benign course. This might be important, because the diagnosis of palindromic rheumatism is based only on clinical criteria. The children inherited from their father the antigens Bw35 and DR4, both of which are known to be connected with rheumatic diseases. HLA Bw35 is increased in the self-limited type of adult Still's disease $^{17}$ and in patients with systemic-onset juvenile rheumatoid arthritis who have limited articular involvement. ${ }^{18}$ DR4 is associated in non-Jews with adult-onset rheumatoid arthritis. ${ }^{1920}$ It should be remembered, however, that the father was clinically healthy and never suffered from any rheumatic disease. Since the disease may be genetically transmitted, and since the mother but not the father suffered from the same disease as the children, it is obvious that the disease segregated with the maternal chromosome.

HLA typing may help to differentiate at a very early stage of the disease between the form which will evolve into rheumatoid arthritis (HLA Aw31 and DR1 in Jews, DR4 in non-Jews) and between juvenile rheumatoid arthritis or palindromic rheumatism. The findings reported above warrant an extensive study of the HLA system in patients and families with palindromic rheumatism.

\section{References}

1 Hardo H G. Palindromic rheumatism: a review. J $R$ Soc Med 1981; 74: 521-4.

2 Mattingly S. Palindromic rheumatism. Ann Rheum Dis 1966; 25: 307-17.

3 Wajed M A, Brown D L, Currey H L F. Palindromic rheumatism: clinical and serum complement study. Ann Rheum Dis 1977; 36: 56-61.

4 Ray J G Jr, ed. Manual of tissue typing techniques. DHEW publication No. (NIH) 75-545. 1974.

5 Bodmer J G, Pickbourne P, Richards S. In: Bodner W F, ed. Histocompatibility testing. Copenhagen: Munksgaard, 1977: 35-84.

6 Hench P S, Rosenberg E F. Palindromic rheumatism: a new oft recurring disease of joints apparently producing no articular residues. Report of 34 cases; its relation to angio-neural arthrosis, allergic rheumatism and rheumatoid arthritis. Arch Intern Med 1944; 73: 293-321.

7 Dunn E C, Jones D W, Mattingly S, Robinson W M, Williams R A. The prognosis of palindromic rheumatism. Ann Rheum Dis 1981; 40: 206-7.

8 Ansell B M, Bywaters E G L. Palindromic rheumatism. Ann Rheum Dis 1959; 18: 331-2.

9 Thompson B, Mohammed I, Holborow E J, Currey H L F. Palindromic rheumatism. II. Failure to detect circulating immune complexes during acute episodes. Ann Rheum Dis 1979; 38: 329-31.

10 Golding D N. D-penicillamine in palindromic theumatism. $\mathrm{Br}$ Med J 1976; ii: 1382.

11 Huskisson E C. Treatment of palindromic rheumatism with penicillamine. $\mathrm{Br}$ Med J 1976; ii: 979.

12 Ginsberg M H, Genant H K, Fan-Yu T, McCarthy D G. Rheumatoid nodulosis: an unusual variant of rheumatoid disease. Arthritis Rheum 1975; 18: 49-58.

13 Margolis J, Margolis L S. Palindromic rheumatism: an allergic manifestation? J Am Geriatr Soc 1977; 25: 189-91.

14 Schiff B, Mizrachi Y, Orgad S, et al. The association of HLA Aw31 and HLA DR1 with adult-onset of rheumatoid arthritis. Ann Rheum Dis 1982; 41: 403-4.

15 Glass D, Litvin K, Wallace L, et al. Early onset pauciarticular juvenile rheumatoid arthritis associated with human leukocyte antigen DRw5, iritis and antinuclear antibody. J Clin Invest 1980; 66: 426-9.

16 Suciu-Foca N, Godfrey M, Jacobs J, et al. Increased frequency of DRw5 in pauciarticular JRA. In: Terasaki P I, ed. Histocompatibility testing. Los Angeles: UCLA Tissue Typing Laboratory, 1980: 953 .

17 Terkeltaub R, Esdaile J M, Decary F, Harth M, Lister J, Lapointe N. HLA Bw35 and prognosis in adult Still's disease. Arthritis Rheum 1981; 24: 1469-72.

18 Glass D N, Litvin D A. Heterogeneity of HLA associations in systemic onset juvenile rheumatoid arthritis. Arthritis Rheum 1980; 23: 796-9.

19 Scherak O, Smolen J S, Mayr W R. Rheumatoid arthritis and B lymphocyte alloantigen HLA DRw4. J Rheumatol 1980; 7: 9-12.

20 Stastny P. Association of the B-cell alloantigen DRw4 with rheumatoid arthritis. $N$ Engl J Med 1978; 298: 869-71. 